\title{
Withdrawal of amoxicillin and penicillin G procaine from milk after intramammary administration in dairy cows with mastitis
}

\author{
Artur Burmańczuk ${ }^{1}$, Grabowski Tomasz ${ }^{2}$, Małgorzata Gbylik-Sikorska ${ }^{3}$, \\ Anna Gajda ${ }^{3}$, Cezary Kowalski ${ }^{1}$ \\ ${ }^{1}$ Department of Pharmacology, Faculty of Veterinary Medicine, \\ University of Life Sciences, 20-033 Lublin, Poland, \\ ${ }^{2}$ Polpharma Biologics, 80-172 Gdańsk, Poland \\ ${ }^{3}$ Department of Pharmacology and Toxicology, National Veterinary Research Institute, 24-100 Pulawy, \\ artur.burmanczuk@up.lublin.pl
}

Received: November 17, 2016

Accepted: March 10, 2017

\begin{abstract}
Introduction: There are many veterinary products containing $\beta$-lactam antibiotics which are used for mastitis treatment in cows. The aim of the study was to determine whether mastitis could have any effect on amoxicillin (AMX) or penicillin G procaine (PEN) withdrawal period from milk, in the context of current maximum residue limits established by the European Commission. Material and Methods: The study was conducted on 17 dairy Black and White cows with clinical mastitis during the lactation period. The first group $(n=8)$ received $200 \mathrm{mg}$ of amoxicillin $($ AMX), whereas the second group $(n=9)$ received 200,000 IU/mg of penicillin G procaine (PEN) by intramammary administration. For the measurement of AMX and PEN concentrations in milk, the liquid chromatography tandem mass spectrometry method was applied. Pharmacokinetic calculations were performed using Phoenix WinNonlin 6.4 software. Results: The determined AMX and PEN half-life values in the mammary gland suggest that the drug withdrawal is at a level of $99.9 \%$ within $81 \mathrm{~h}(\approx 3.5$ days $)$ and $116 \mathrm{~h}(\approx 5$ days $)$ after administration of AMX and PEN, respectively. The present research indicates that, at $60 \mathrm{~h}$ after administration, the average PEN concentration in the milk from cows with clinical signs of mastitis may still reach $4.96 \mathrm{~g} / \mathrm{kg}$ and that of AMX can even be $6.92 \mathrm{~g} / \mathrm{kg}$. Conclusion: The results obtained confirm that, in mastitis cases, a 72-h withdrawal period is sufficient for elimination of AMX to a lower level than the established maximum residue limit (MRL) values. However, in the case of PEN, at $69 \mathrm{~h}$ after administration, the drug concentration may be close to that of the determined MRL.
\end{abstract}

Keywords: cows, milk, amoxicillin, penicillin G procaine, pharmacokinetics.

\section{Introduction}

According to the European Commission (EC) report, which presents a medium-term outlook for the major European Union (EU) agricultural commodity markets and agricultural income to 2024, the expansion of EU milk production is limited by increasing levels of production in competing regions (17). However, the large-scale production in some EU countries is associated with great responsibility and the need for the best practice to maintain quality (17). Inflammation of the mammary gland in cows is an important sanitary, epidemiological, and economical issue. Introduction of therapeutic agents into udder quarters, emptied from inflammatory secretions, if not accompanied by inflammation of the overall reaction system, is a principle in the treatment of mastitis. There are a number of veterinary products containing $\beta$-lactam antibiotics in their composition, which are used for mastitis treatment in cows $(4,6,9,24)$. One of the $\beta$-lactam antibiotic groups are aminopenicillins, including penicillin $\mathrm{G}$ procaine $(\mathrm{PEN})$ and amoxicillin (AMX) $(6,25)$. Penicillins are commonly used in veterinary medicine due to their broad spectrum of activity when confronted with natural penicillins, low treatment cost and safety $(24,25)$. When collated with penicillins $\mathrm{G}$, aminopenicillin has a better ability of penetration of the external cell membrane layer and, consequently, it has a much broader spectrum of activity against many Gram negative bacteria (e.g. 
Enterobacteriaceae spp.) (24). A severe limitation in their therapeutic use is the increasing resistance of bacteria to PEN and $\operatorname{AMX}(6,25,30,33)$.

Uncontrolled use of aminopenicillins and penicillins in animal treatment may result in the presence of antibiotic residues in food of animal origin $(6,27,30$, 31). However, the risk to human health is posed by antibiotic residues in milk produced by cattle treated for mammary gland inflammation $(6,22)$. Due to the potential impact on human health, the EC established maximum residue limits (MRLs) for PEN and AMX in milk at the level of $4 \mu \mathrm{g} / \mathrm{kg}$ (11). For this reason, pharmacokinetic studies with aminopenicillin and penicillin were conducted in order to determine their withdrawal periods in milk. It should be noted that determination of withdrawal periods and MRL values does not involve comparative analysis and parallel or cross-over examinations of healthy and diseased animals. The withdrawal period is established exclusively in a group of healthy animals (10).

The aim of the study was to determine whether mastitis could have any effect on AMX or PEN withdrawal from the cow milk. The study involved cows with clinical symptoms of mastitis receiving intramammary doses of the analysed drugs. The determination of the concentration of AMX and PEN in milk was performed by a validated and selective liquid chromatography tandem mass spectrometry method.

\section{Material and Methods}

The study was conducted on 17 dairy cows of the Polish Black-White breed at the age of 4-10 years with clinical mastitis during the lactation period. The cows were examined in different lactation periods, i.e. from 1.5 month post-calving to the pre-drying period; the average milk yield per cow was ca. $25-30 \mathrm{~L} / 24 \mathrm{~h}$. The cows weighed approx. $650 \mathrm{~kg}$ each. They were qualified for the research on the basis of guidance from the owners and research exchanges (12). According to the EMA guidelines, subclinical mastitis is diagnosed if somatic cell count (SCC) is over 200,000 cells $/ \mathrm{mL}$ (12). The cows were verified using a mastitis detector DRAMINSKI Mastitis Detector $4 \times 4 \mathrm{Q}$, a 4 -quarter device for detecting subclinical mastitis in its earliest, visually undetectable stage (Dramiński, Poland), in order to assess the SCC. Cows with SCC $\geq 400,000 / \mathrm{mL}$ were qualified for the study. The animals were fed farming feed concentrates comprising commercial (wheat, rye) and fodder (oats, barley) grain alternating with raw corn and pasture grazing. Access to feed and water was provided ad libitum. The analyses were carried out between March and September. The cows originated from different farms in the Lublin Province area. The first group of cows $(\mathrm{n}=8)$ received a $5 \mathrm{~mL}$ water solution containing $200 \mathrm{mg}$ of AMX (Synulox L.C., Pfizer, Poland), whereas the second group $(\mathrm{n}=7)$ received a $5 \mathrm{~mL}$ water solution containing 200,000 IU/mg of PEN (Albadry Plus, Zoetis, Poland) by intramuscular administration. PEN and AMX were used as indicated by the manufacturer's label. Before the process of milk sample collection, the teats were cleaned and immersed in a liquid disinfectant, Avitaderm (Agrovet, Poland). Afterwards, their mouths were wiped with a swab soaked in $70 \%$ ethanol. Subsequently, after single intramuscular administration, the milk samples $(10 \mathrm{~mL})$ were collected at the following time points: PEN after 2, $4,6,8,10,24,36,48$, and $60 \mathrm{~h}$ and AMX after 2, 4, 6, $8,10,24,36,48$, and $72 \mathrm{~h}$. The milk samples were collected into dark plastic bottles and kept in a cooler at $-18^{\circ} \mathrm{C}$ until analysis.

For the measurement of AMX and PEN concentrations in milk, LC-MS/MS method was applied, based on a previously described procedure for determination of antibiotics in muscle tissues, including AMX and PEN (2). The extraction of AMX and PEN with acetonitrile established for muscles was found suitable for the isolation of these two compounds from the milk matrix. Sample preparation procedure for AMX and PEN in milk was the same as the procedure used for muscle tissue. The only difference between the analysis described by Błądek et al. (2) and the method used in the presented study was the omission of the homogenisation step before the extraction. Two grams of milk were directly weighed into a polypropylene centrifuge tube and $8 \mathrm{~mL}$ of acetonitrile was added in the extraction step. The same LC-MS/MS conditions and analytical equipment were used. The chromatographic separation of AMX and PEN performed on the Luna ${ }^{\circledR}$ octadecyl C18 column $150 \times 2.0 \mathrm{~mm}, 3 \mu \mathrm{m}$ with the mobile phase consisting of acetonitrile and $0.025 \%$ heptafluorobutyric acid was also suitable for the milk samples. For the purposes of the conducted study, the whole validation procedure for the milk matrix was performed. The method used in the presented experiment was fully validated in accordance to Commission Decision 2002/657/EC (16). During the validation process, various parameters were investigated, such as linearity, precision (repeatability and within-laboratory reproducibility), accuracy, decision limit $\left(\mathrm{CC}_{\alpha}\right)$, and detection capability $\left(\mathrm{CC}_{\beta}\right)$. Additionally, the limit of detection (LOD) and the limit of quantification (LOQ) were established. For linearity, a matrix-matched calibration curve was prepared in duplicate at the range of $2-10,000 \mu \mathrm{g} / \mathrm{kg}$. The validation results showed acceptable linear response. The correlation coefficients for AMX and PEN were over R $>0.99$. Precision was determined by the repeated analysis $(n=6)$ of milk samples spiked with analytes at concentrations corresponding to $0.5 \times \mathrm{MRL}, \mathrm{MRL}$, and $1.5 \times \mathrm{MRL}$, between runs during one and three days, respectively. The validation results obtained for the presented method were repeatable and reproducible with the repeatability calculated as a percentage of relative standard deviation (RSD\%) lower than $15 \%$ at all fortification levels and within-laboratory reproducibility lower than $20 \%$. The overall coefficient of variations (CVs) for both analytes was in the range of $9.8 \%-13.6 \%$ for repeatability and $9.2 \%-15.8 \%$ for within-laboratory reproducibility. The 
validation results showed acceptable accuracy with the average recoveries ranging from $93.3 \%$ to $96.4 \%$ for AMX and from $93.2 \%$ to $95.5 \%$ for PEN. The $\mathrm{CC}_{\alpha}$ and $\mathrm{CC}_{\beta}$ for AMX were $5 \mu \mathrm{g} / \mathrm{kg}$ and $7 \mu \mathrm{g} / \mathrm{kg}$, respectively. The $\mathrm{CC}_{\alpha}$ and $\mathrm{CC}_{\beta}$ of PEN were established at $4 \mu \mathrm{g} / \mathrm{kg}$ and $6 \mu \mathrm{g} / \mathrm{kg}$, respectively. The procedure was satisfactorily sensitive with LOD $=1 \mu \mathrm{g} / \mathrm{kg}$ and LOQ $=$ $2 \mu \mathrm{g} / \mathrm{kg}$ for both analytes.

Pharmacokinetic and statistical analysis. The pharmacokinetic calculations were performed based on raw data using Phoenix ${ }^{\circledR}$ WinNonlin ${ }^{\circledR} 6.4$ software (Certara L.P., USA) and the statistical analyses were carried out with GraphPad Prism ${ }^{\circledR} 6.01$ programme (GraphPad Software Inc., USA). The calculations were based on the slope, height, area, and moment (SHAM) analysis, and a modified two-compartment model of drug distribution. The following parameters were calculated with the SHAM analysis: $\mathrm{AUC}_{0-\mathrm{t}}-$ area under the curve calculated between zero and the last sampling point; $\mathrm{AUC}_{0 \text {-inf }}$ - area under the curve calculated between zero and infinity; $\mathrm{AUMC}_{0-\mathrm{t}}$ - area under the first moment curve calculated between zero and the last sampling point; $\mathrm{AUMC}_{0 \text {-inf }}$ - area under the first moment curve calculated between zero and infinity; $\mathrm{MRT}_{0-\mathrm{t}}-$ mean residence time calculated for the last sampling point; $\mathrm{MRT}_{0 \text {-inf }}$ - mean residence time calculated for infinity; $\mathrm{AUC}_{\mathrm{rest} \%}$ - percentage of the rest area under the curve; $\mathrm{C}_{\max }-$ maximal concentration; $\mathrm{t}_{\max }$ - time to reaching maximal concentration; $\mathrm{C}_{\text {last }}$ - last measured concentration; $t_{\text {last }}$ - time of the last measured concentration; $\mathrm{k}_{\mathrm{el}}$ - elimination rate constant. As part of the compartment analysis, the following were additionally calculated: $\mathrm{k}_{\mathrm{d}}$ - distribution rate constant; $\mathrm{t}_{1 / 2 \mathrm{kel}}$ - elimination half-life; $\mathrm{t}_{1 / 2 \mathrm{kd}}$ - distribution half-life; B - concentration extrapolated by elimination phase; A - concentration extrapolated by distribution phase; $\mathrm{k}_{10}$ - elimination rate from milk (central) compartment; $\mathrm{k}_{20}$ - elimination rate from tissue compartment; $\mathrm{k}_{12}$ - rate constant between milk and tissue concentration; $\mathrm{k}_{21}$ - rate constant between tissue and milk concentration; $\mathrm{CL}$ - total clearance; $\mathrm{V}_{1}-$ milk compartment volume; $\mathrm{V}_{2}$ - tissue compartment.

The compartment analysis distinguished two compartments. The first one was the central compartment comprising milk present in the teat canal and teat sinuses. Udder tissues were defined as the second compartment. Therefore, the distribution rate constant $\mathrm{k}_{\mathrm{d}}$ illustrates the elimination rate constant for drug withdrawal with milk. Hence, the equation for calculation of the AMX and PEN concentrations at any time point $(\mathrm{Cp})$ following intramuscular administration has a typical structure of the two-compartment model:

$$
C p=A \times e^{-k_{d} \times t}+B \times e^{-k_{e l} \times t} \quad \text { (Eq. 1) }
$$

In turn, the elimination rate constant $\mathrm{k}_{\mathrm{el}}$ represents drug transfer from milk to tissues. Between-animal variability was shown as percentage of relative standard deviation (RSD). A $t$-student test was employed to confirm the significance of these observations. Differences with a $\mathrm{P}<0.05$ were considered significant.

\section{Results}

The results of chromatographic measurements of AMX and PEN in cow's milk after intramuscular administration are shown in Table 1 and Figs 1A and 1B. An immediate maximal concentration of the drugs in plasma can be observed after intramuscular administration. Next, it decreases quickly as a result of distribution with milk into the tissue compartment. The difference in the chemical structure in the key parameters between the studied drugs is not significant. Lipophilicity $(\mathrm{X} \log \mathrm{P})$, topological polar surface area, hydrogen bond donors, and hydrogen bond acceptors in the case of AMX and PEN are -2, $158 \AA^{2}, 4,7$ and 1.8 (penicillin G), $169 \AA^{2}, 4,10$, respectively
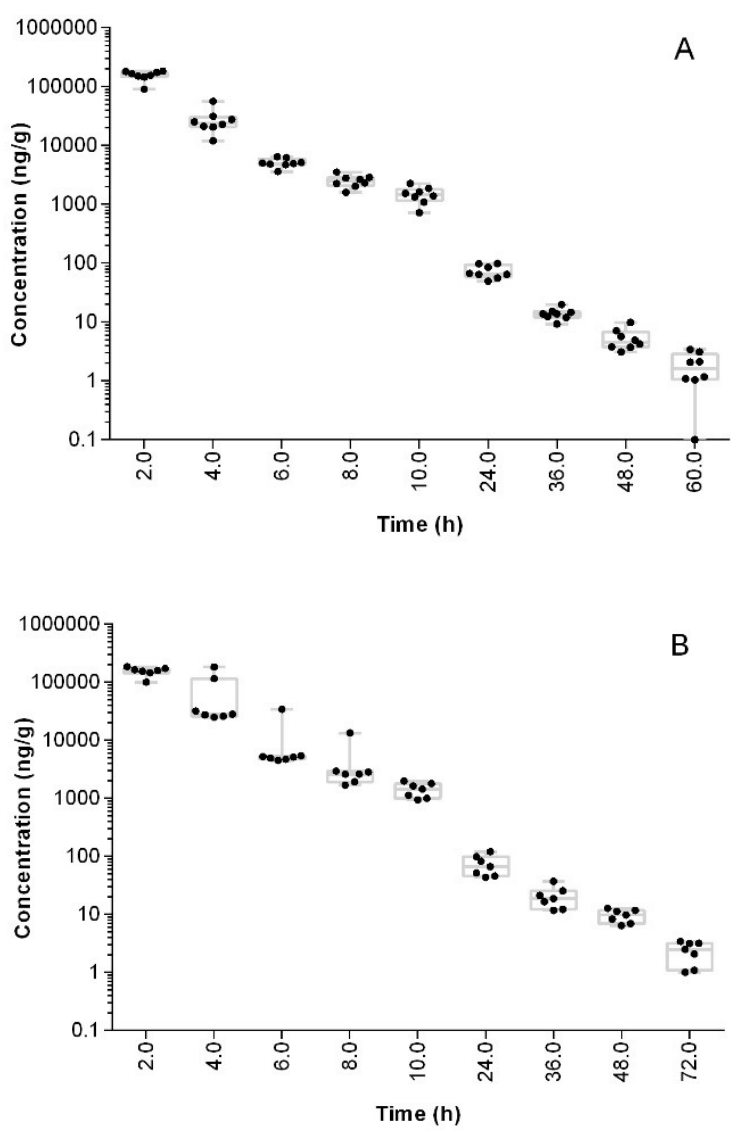

Fig. 1. Kinetics of withdrawal of amoxicillin (A) and penicillin $G$ procaine $(B)$ after a single intramammary administration of the drug at a dose of $200 \mathrm{mg}$ and 200,000 IU/mg, respectively

The results of the pharmacokinetic analysis are presented in Table 1. The calculations indicate that PEN in the intramammary formulation can be classified as a drug with high individual variability. This variability in the case of $\mathrm{PEN}$ in relation to $\mathrm{AUC}_{0-\mathrm{t}}$ was $>30 \%$. The same parameter in the case of AMX was only $18 \%$. However, in the case of $\mathrm{C}_{\max }$, both AMX and PEN exhibited low values of individual variability, i.e. $18 \%$ and $17 \%$, respectively. It should be noted that the individual variability in the case of the other analysed parameters was low and at a similar level (AMX vs. PEN), 
Table 1. Pharmacokinetic parameters describing the behaviour of the amoxicillin and penicillin $\mathrm{G}$ procaine after a single intramammary administration of the drug at a dose of $200 \mathrm{mg}$ and 200,000 IU/mg, respectively

\begin{tabular}{|c|c|c|c|c|c|}
\hline \multirow{2}{*}{ PK parameters } & \multirow{2}{*}{ Unit } & \multicolumn{2}{|l|}{ Amoxicillin } & \multicolumn{2}{|c|}{ Penicillin G procaine } \\
\hline & & $\mathbf{M}$ & SD & $\mathbf{M}$ & SD \\
\hline $\mathrm{AUC}_{0-\mathrm{t}}$ & $\mathrm{g} \times \mathrm{h} / \mathrm{kg}$ & 391974.52 & 69043.63 & 471040.97 & 146203.3 \\
\hline $\mathrm{AUC}_{0 \text {-inf }}$ & $\mathrm{g} \times \mathrm{h} / \mathrm{kg}$ & 391998.61 & 69045.23 & 471080.73 & 146209.5 \\
\hline $\mathrm{AUMC}_{0-\mathrm{t}}$ & $\mathrm{g} \times \mathrm{h}^{2} / \mathrm{kg}$ & 1087333.96 & 207114.07 & 1441652.85 & 588232.58 \\
\hline $\mathrm{AUMC}_{0 \text {-inf }}$ & $\mathrm{g} \times \mathrm{h}^{2} / \mathrm{kg}$ & 1089094.32 & 207140.19 & 1445211.84 & 588599.82 \\
\hline $\mathrm{AUC}_{\mathrm{rest} \%}$ & $\%$ & 0.01 & 0.0 & 0.01 & 0.0 \\
\hline $\mathrm{MRT}_{0-\mathrm{t}}$ & $\mathrm{h}$ & 2.77 & 0.13 & 2.99 & 0.3 \\
\hline $\mathrm{MRT}_{0 \text {-inf }}$ & $\mathrm{h}$ & 2.78 & 0.13 & 2.99 & 0.3 \\
\hline $\mathrm{k}_{\mathrm{el}}$ & $1 / \mathrm{h}$ & $0.088 *$ & 0.016 & $0.061 *$ & 0.008 \\
\hline $\mathrm{k}_{\mathrm{d}}$ & $1 / \mathrm{h}$ & 0.805 & 0.106 & 0.857 & 0.118 \\
\hline B & $\mathrm{g} / \mathrm{kg}$ & 403.45 & 242.04 & 191.73 & 84.11 \\
\hline $\mathrm{A}$ & $\mathrm{g} / \mathrm{kg}$ & 747130.27 & 276354.99 & 1911448.46 & 2530672.32 \\
\hline $\mathrm{t}_{1 / 2 \mathrm{kel}}$ & $\mathrm{h}$ & $8.11 *$ & 1.55 & $11.61 *$ & 1.68 \\
\hline $\mathrm{t}_{1 / 2 \mathrm{kd}}$ & $\mathrm{h}$ & 0.88 & 0.13 & 0.82 & 0.12 \\
\hline $\mathrm{C}_{\max }$ & $\mathrm{g} / \mathrm{kg}$ & 154850.0 & 27867.68 & 156571.43 & 27191.69 \\
\hline $\mathrm{t}_{\max }$ & $\mathrm{h}$ & 2.0 & 0.0 & 2.29 & 0.7 \\
\hline $\mathrm{C}_{\text {last }}$ & $\mathrm{g} / \mathrm{kg}$ & 1.75 & 1.07 & 2.35 & 0.93 \\
\hline $\mathrm{t}_{\text {last }}$ & $\mathrm{g} / \mathrm{kg}$ & 60.0 & 0.0 & 72.0 & 0.0 \\
\hline $\mathrm{k}_{10}$ & $1 / \mathrm{h}$ & 0.802 & 0.107 & 0.854 & 0.117 \\
\hline $\mathrm{k}_{21}$ & $1 / \mathrm{h}$ & $0.089 *$ & 0.017 & $0.061^{*}$ & 0.008 \\
\hline $\mathrm{k}_{12}$ & $1 / \mathrm{h}$ & 0.003 & 0.001 & 0.002 & 0.001 \\
\hline $\mathrm{k}_{20}$ & $1 / \mathrm{h}$ & 25.26 & 7.368 & 44.81 & 40.905 \\
\hline $\mathrm{CL}$ & $\mathrm{L}$ & 0.535 & 0.143 & 0.467 & 0.143 \\
\hline $\mathrm{V}_{1}$ & $\mathrm{~kg}$ & 0.344 & 0.214 & 0.212 & 0.102 \\
\hline $\mathrm{V}_{2}$ & $\mathrm{~kg}$ & 10.08 & 5.32 & 8.368 & 3.584 \\
\hline
\end{tabular}

$\mathrm{M}$ - arithmetic mean; SD - standard deviation; $\mathrm{AUC}_{0-\mathrm{t}}$ - area under the curve calculated between zero and last sampling point; $\mathrm{AUC}_{0 \text {-inf }}$ - area under the curve calculated between zero and infinity; $\mathrm{AUMC}_{0-\mathrm{t}}-$ area under the first moment of curve calculated between zero and last sampling point; $\mathrm{AUMC}_{0 \text {-inf }}-$ area under the first moment of curve calculated between zero and infinity; $\mathrm{MRT}_{0-\mathrm{t}}-$ mean residence time calculated for last sampling point; $\mathrm{MRT}_{0 \text {-inf }}-$ mean residence time calculated for infinity; $\mathrm{AUC}_{\mathrm{rest} \%}$ - percentage of the rest area under the curve; $\mathrm{C}_{\max }$ - maximal concentration; $t_{\max }-$ time to rich maximal concentration; $\mathrm{C}_{\text {last }}$ - last measured concentration; $\mathrm{t}_{\text {last }}$ - time of last measured concentration; $\mathrm{k}_{\mathrm{el}}$ - elimination rate constant; $\mathrm{k}_{\mathrm{d}}$ - distribution rate constant; $\mathrm{t}_{1 / 2 \mathrm{kel}}$ - elimination half-life; $\mathrm{t}_{1 / 2 \mathrm{kd}}$ - distribution half-life; $\mathrm{B}$ - concentration extrapolated by elimination phase; $\mathrm{A}$ - concentration extrapolated by distribution phase; $\mathrm{k}_{10}$ - elimination rate from milk compartment $\mathrm{k}_{20}$ - elimination rate from tissue compartment; $\mathrm{k}_{12}$ - rate constant between milk and tissue concentration; $\mathrm{k}_{21}-$ rate constan between tissue and milk concentration; $\mathrm{CL}$ - total clearance; $\mathrm{V}_{1}-$ milk compartment volume; $\mathrm{V}_{2}-$ tissue compartment; $*-\mathrm{P}<0.05$

but significant differences were found in some cases. The variability of the $\mathrm{k}_{12}$ and $\mathrm{k}_{20}$ values $(\mathrm{RSD} \approx 67 \%$ ) was two- and three-fold higher, respectively, than that in the case of PEN. The variability of $A(R S D \approx 132 \%)$ was 3.6-fold higher than that of PEN. The proposed twocompartment model was verified by the calculations. The $\mathrm{k}_{\mathrm{d}} / \mathrm{k}_{\mathrm{el}}$ value for AMX and PEN was 9.1 and 14.1, respectively. This indicates that processes referred to as distribution reached 9- and 14-fold higher rates than the determined $\mathrm{k}_{\mathrm{el}}$. The $\mathrm{t}_{1 / 2 \mathrm{kel}}$ calculated on the basis of $\mathrm{MRT}_{0-\mathrm{t}}$ was 4.1- and 5.5-fold shorter than that calculated based on $\mathrm{k}_{\mathrm{el}}$. Sampling was carried out at 7.4 and 6.2 half-lives after administration of AMX and PEN, respectively. This allowed the maintenance of the minimal values of the residue area at a very low level (Table 1). The determined AMX and PEN half-life values in the mammary gland suggest AMX and PEN withdrawal at a level of $99.9 \%\left(10 \times \mathrm{t}_{1 / 2 \mathrm{kel}}\right)$ within the time of $81 \mathrm{~h}(\approx 3.5$ days $)$ and $116 \mathrm{~h}(\approx 5$ days $)$ after administration of the drug, respectively. The kinetics of both drugs, particularly in terms of the analysis of rate constants, was highly similar. Significant differences were only evident in the case of $\mathrm{k}_{\mathrm{el}}, \mathrm{t}_{1 / 2 \mathrm{kel}}$, and $\mathrm{k}_{21}$ (Table 1 ).

\section{Discussion}

Pharmacokinetic profiles of AMX and AMP in animals have been presented in several publications $(7$, $8,9,14,15,20,21,29)$. Ampicillin has been studied in alpacas (28), llamas $(5,29)$, lactating sheep and goats (15), cattle (12), female buffaloes (26), and neonatal calves (21). The pharmacokinetic profile of AMX has been investigated in sheep and goats $(7,8,9,14,20)$. However, up to now, there has been no detailed research involving AMX and PEN pharmacokinetics in milk after IM administration to cows of the Black and White breed showing signs of clinical mastitis.

In the present study, after intramuscular administration of AMX and PEN, both substances were detectable with the use of LC-MS/MS in milk for 60-72 h after single drug administration. Parenterally administered acidic antibiotics are quickly eliminated from milk $(6,9,23,24)$. After intravenous administration, the AMX and PEN elimination half-lives are 7.5 to $11.8 \mathrm{~h}$, respectively $(1,14,21,32)$. Furthermore, quick AMX elimination from milk ( $48 \mathrm{~h}$ ) was observed after intravenous administration in llamas (29). 
The above-mentioned results of the sustenance time of AMX and PEN in milk after intravenous administration indicate limited suitability of the parenteral use of these antibiotics in mastitis treatment. A high rate of elimination with a large decrease in the concentration of AMX and PEN was recorded within $12 \mathrm{~h}$ after intramuscular administration of the drugs. In the study conducted by Bruno et al. (3) milk samples were taken after intramuscular administration of $5 \mathrm{~g}$ of AMX $(\mathrm{n}=1)$. Three days later the AMX concentration was $2.7 \mathrm{~g} / \mathrm{L}$ and after six days $1.2 \mathrm{~g} / \mathrm{L}$. This means that the half-life in this phase was $\approx 61 \mathrm{~h}$. The present research was carried out on cows of Black and White breed at $\mathrm{C}_{\text {last }}=72 \mathrm{~h}$; hence, it was difficult to verify the AMX half-life in the period between days 3 and 6 after administration of the drug. The investigations reported by Bruno et al. (3) were performed on milk from one cow only. The breed of the cow from which milk was sampled was not specified $(n=1)$. However, the results obtained by the authors indicate fluctuating or non-linear characteristics of AMX elimination.

Undoubtedly, the pharmacokinetic profiles of AMX and PEN are highly similar. The differences observed are definitely negligible and mostly statistically insignificant $(\mathrm{P}>005)$. An interesting element of the AMX and PEN kinetics is the fact that both drugs administered via the intramuscular route are characterised by typical two-compartment kinetics. The distribution of both drugs to the tissue compartment is definitely a separate kinetic phase. This implies that the transfer from tissues into milk and from udder tissues to systemic circulation is an important element of elimination of the drugs. However, the $\mathrm{V}_{2}$ value seems negligible. The results of the analyses indicate that it ranges from 5 to $15 \mathrm{~kg}$ of tissue. Therefore, a hypothesis can be proposed that elimination of the drugs proceeds in udder tissues and they hardly reach systemic circulation. The $\mathrm{k}_{\mathrm{d}}$ in the adopted model is of particular importance. One of the elements of distribution is drug withdrawal from milk; however, the high dynamics of this phase is maintained in both cases only until ca. $12 \mathrm{~h}$ after administration of the drugs. Hence, AMX and PEN elimination is not dependent on production of milk by the mammary gland only. During the subsequent postadministration hours, the concentration curve slope is remarkably milder and drug elimination is mainly dependent on the mutual ratio of the $\mathrm{k}_{12}, \mathrm{k}_{21}$, and $\mathrm{k}_{10}$ rate constants. In the case of both drugs, $\mathrm{k}_{20}$ has very high values, which means that the drug is eliminated from the tissue compartment at a very high rate. Assuming that $\mathrm{k}_{10}$ denotes a drug withdrawn from milk, the rate of AMX and PEN elimination from tissues is 31- and 52-fold higher, respectively, than the rate of drug withdrawal from milk. In both cases, however, the drug transfer to tissues is a relatively slow process. This is indicated by the $\mathrm{k}_{21} / \mathrm{k}_{12}$ ratio, which shows that the AMX and PEN transfer from milk to tissues is 30 and 33 times slower than that from tissues to milk. This fact explains e.g. the very fast rate of elimination of both drugs from the tissue compartment $\left(\mathrm{k}_{20}\right)$.

The calculations reveal that at $60 \mathrm{~h}$ after a single intramuscular administration, the AMX concentration in milk is $2.0 \mathrm{~g} / \mathrm{kg}$. Notably, the individual variability of this time point in the case of AMX reaches $61 \%$. This means that, at $60 \mathrm{~h}$ after administration, the drug concentration may reach a level of even $3.22 \mathrm{~g} / \mathrm{kg}$. It should be noted that in the USA, France, and Portugal, the withdrawal period for milk from cows treated with intramammary AMX formulations is only $24 \mathrm{~h}(12,18)$. However, the presented calculations show that the AMX concentration in milk from Black and White breed cows with signs of clinical mastitis at $24 \mathrm{~h}$ after administration of a dose of $200 \mathrm{~g}$ of the drug can have an even 12-fold higher mean value ( $>48 \mathrm{~g} / \mathrm{kg})$ than MRL ( $4 \mathrm{mg} / \mathrm{kg})$.

After a single intramuscular administration, PEN concentration calculated using Eq. 1 after $69 \mathrm{~h}$ is $2.87 \mathrm{~g} / \mathrm{kg}$. The individual variability for this time point in the case of PEN is 39\%. Therefore, $69 \mathrm{~h}$ after PEN administration the concentration of the drug may still exhibit a level of $3.99 \mathrm{~g} / \mathrm{kg}$, i.e. a value close to MRL. At the variability mentioned above, PEN concentration equal to $0.5 \times \mathrm{MRL}$ can be achieved at $80 \mathrm{~h}$ after administration of the drug. The results obtained confirm that in mastitis cases, a 72-h withdrawal period is sufficient for elimination of AMX to a lower level than the established MRL values. However, in the case of $\mathrm{PEN}$, at $69 \mathrm{~h}$ after administration the drug concentration may be close to that of the determined MRL. This implies that, depending on the individual variability, differences among breeds, variation in nutrition, or changes in the udder blood flow, the threshold can be exceeded. It should be added that the PEN withdrawal period was established in the USA at $60 \mathrm{~h}$ for lactating cows and $72 \mathrm{~h}$ for cows in the dry period (19). The present study, however, demonstrates that a 60 -h postadministration period in the case of PEN is not sufficient to reach concentrations corresponding to the standards established by the EC. The present research indicates that at $60 \mathrm{~h}$ after administration, the average PEN concentration of the drug in the milk from Black and White breed cows with clinical signs of mastitis may reach $4.96 \mathrm{~g} / \mathrm{kg}$ with $39 \%$ between-animal variability. In the case of AMX, mastitis has no significant impact on the withdrawal period and the safety of application of intramammary formulations. Therefore, the presented results are consistent with those obtained in investigations on healthy cows, which were the basis for recording and establishment of the withdrawal period for the original formulation (10).

Guidelines regulating aspects related to the calculation of MRLs for drugs administered via the intramuscular route emphasise the role of selection of cattle intended for investigations (13). Regulatory authorities attach a significant role to the impact of the cattle breed on the rate of drug withdrawal in milk. The present study was carried out on the Black and White 
breed, for which the kinetics of AMX and PEN elimination in the case of mastitis has not been described yet.

The lack of harmonised requirements for the levels of AMX and PEN residues in milk at the level of the International Conference of Harmonisation still impedes uniform control of the residues of these drugs in milk at a global scale. In the area of EMA influences, the admissible level of AMX and PEN residues is $4 \mathrm{~g} / \mathrm{kg}$; in turn, in regions influenced by the FDA, the values are $10 \mathrm{~g} / \mathrm{kg}(\mathrm{AMX})$ and $0 \mathrm{~g} / \mathrm{kg}$ (PEN) $(18,19)$. There are no regulations concerning the cattle breed that can be used in investigations of drug residues and regarded as a representative breed. Neither are there regulations for elimination periods for drugs with kinetics partly dependent on blood flow through the mammary gland. Blood flow can be influenced not only by the form and course of mastitis, but also by individual differences or differences related to breed, and lactation phase, and consequently those related to the cardiac output. These issues have still not been defined by relevant guidelines. The present study indicates that there are still real potential risks for consumers and milk processing industry.

Conflict of Interests Statement: The authors declare that there is no conflict of interests regarding the publication of this article.

Financial Disclosure Statement: This work was financially supported by the Ministry of Science and Higher Education (NCN Project No. N N308 603 438).

Animal Rights Statement: The experiment was carried out with the approval of the Local Ethical Committee in Lublin.

\section{References}

1. Bengtsson B., Jacobsson S.O., Luthman J., Franklin A.: Pharmacokinetics of penicillin-G in ewes and cows in late pregnancy and in early lactation. J Vet Pharmacol Ther 1997, 20, 258-261

2. Błądek T, Posyniak A, Gajda A, Gbylik M, Żmudzki J.: Multiclass procedure for analysis of antibacterial compounds in animal tissues by liquid chromatography tandem mass spectrometry. Bull Vet Inst Pulawy 2011, 55, 741-748.

3. Bruno F., Curini R., di Corcia A., Nazzari M., Samperi R.: Solidphase extraction followed by liquid chromatography-mass spectrometry for trace determination of beta-lactam antibiotics in bovine milk. J Agric Food Chem 2001, 49, 3463-3470.

4. Burmańczuk A., Roliński Z., Kowalski C., Zań R.: Pharmacokinetic - pharmacodynamic model and ampicillin residue depletion after intramammary administration in cows. J Vet Res 2016, 60, 169-176.

5. Christensen J.M., Smith B.B., Murdena S.B., Hollingshead N.: The disposition of five therapeutically important antimicrobial agents in llamas. J Vet Pharmacol Ther 1996, 19, 431-438.

6. Concordet D., Toutain P.L.: The withdrawal time estimation of veterinary drugs revisited. J Vet Pharmacol Ther 1997, 20, 380 386.
7. Craigmill A.L., Pass M.A., Wetzlich S.: Comparative pharmacokinetics of AMX administered intravenously to sheep and goats. J Vet Pharmacol Ther 1992, 15, 72-77.

8. Delis G.A., Koutsoviti-Papadopoulou M., Siarkou V.I., Kounenis G., Batzias G.C.: Pharmacodynamics of amoxicillin against Mannheimia haemolytica and Pasteurella multocida and pharmacokinetic/pharmacodynamic (PK/PD) correlation in sheep. Res Vet Sci 2010, 89, 418-425.

9. Elsheikh H.A., Taha A., Khalafalla A., Osman I., Wasfi I.: Pharmacokinetics of amoxicillin trihydrate in Desert sheep and Nubian goats. Vet Res Commun 1999, 23, 507-514.

10. EMA European Medicines Agency. Synulox Lactating Cow Article 34 referral- Annexes I, II, and III 2011, pp. 1-25.

11. EMA European Medicines Agency/Committee for Medicinal Products for Veterinary Use (CVMP). Penicillins Summary Report 2008, pp. 1-2.

12. EMA European Medicines Agency/Committee for Medicinal products for Veterinary Use (CVMP) 2013/EWP/141272/2011, pp. 4-5.

13. EMA European Medicines Agency/Committee for Medicinal Products for Veterinary Use (CVMP). Guideline on withdrawal periods for milk 2000, pp. 1-26.

14. Escudero E., Cárceles C.M., Vicente S.: Pharmacokinetics of amoxicillin/clavulanic acid combination and of both drugs alone after intravenous administration to goats. Br Vet J 1998, 152, $551-559$

15. Escudero E., Espuny A., Vicente M.S., Cárceles C.M.: Comparative pharmacokinetics of an ampicillin/sulbactam combination administered intramuscularly in lactating sheep and goats. Can J Vet Res Jan 1999, 63, 25-30.

16. EU Commission. Decision 2002/657/EC Implementing Council Directive 96/23/EC concerning the performance of analytical methods and the interpretation of results 2002, L221, 8-36.

17. EU Commission. Agriculture and Rural Development, Markets and prices, Medium-term prospects for EU agricultural markets and income 2015, 2015-2025.

18. FDA Food and Drug Administration. Chapter I - food and drug administration department of health and human services. subchapter e - animal drugs, feeds, and related products. part 526 - Intramammary dosage form new animal drugs. Sect. 526.1696a - Penicillin G procaine. Title 21, Volume 6, Revised as of April 1 2015.

19. FDA Food and Drug Administration. Chapter I - food and drug administration department of health and human services. subchapter e - animal drugs, feeds, and related products. part 526 - intramammary dosage form new animal drugs. Sect. 526.1696a - Amoxicillin trihydrate. Title 21, Volume 6, Revised as of April 12015.

20. Fernandez C., Modamio P., Mestorino N., Errecalde J.O., Marino E.L.: Pharmacokinetics of sodium and trihydrate amoxycillin in sheep after intravenous and intramuscular administration. J Vet Pharmacol Ther 2007, 30, 263-266.

21. Fernandez-Varon E., Escudero-Pastor E., Carceles-Rodriguez C.: Pharmacokinetics of an ampicillin-sulbactam combination after intravenous and intramuscular administration to neonatal calves. Vet J 2005, 169, 437-443.

22. Frimodt-Moller N.: How predictive is PK/PD for antibacterial agents? Int J Antimicrob Ag 2002, 19, 333-339.

23. Gibaldi M., Perrier D.: Pharmacokinetics. edited by Marcel Dekker, New York 1982.

24. Guterbock W.W., Eenennaam A.L., Anderson R.J., Gardner I.A., Cullor J.S., Homberg C.A.: Efficacy of intramammary antibiotic therapy for treatment of clinical mastitis caused by environmental pathogens. J Dairy Sci 1993, 76, 3437-3441.

25. Jacoby G.A., Munoz-Price L.S.: The new beta-lactamases. NEJM 2005, 352, 380-391

26. Jayachandran C., Singh M.K., Banerjee N.C.: Pharmacokinetics and distribution of ampicillin in plasma, milk and uterine fluid of female buffaloes. Vet Res Commun 1990, 14, 47-51. 
27. Khaskheli M., Malik R.S., Arain M.A., Soomro A.H., Arain H.H.: Detection of beta-lactam antibiotic residues in market milk. Pak J Nutr 2008, 7, 682-585.

28. Kreil V., Lüders C., Hallu R., Rebuelto M., Betancourt L.: Pharmacokinetics of ampicillin in Alpacas (Lama pacos). Arch Med Vet 2001, 2, 241-246.

29. Kreil V.E., Ambros L., Montoya L., Hallu R., Rebuelto M., Bramuglia G.: Pharmacokinetics of sodium and trihydrate amoxicillin after intravenous and intramuscular administration in llamas (Lama glama). Small Ruminant Res 2012, 102, 208-212.

30. Movassagh M.H., Karami A.R.: Beta-lactam antibiotics residues in pasteurised milk by Beta Star test in the north west region of Iran. ARPN J Agri Biol Sci 2011, 6, 7-10.
31. Nisha A.R.: Antibiotic residues - a global health hazard. Vet World 2008, 1, 375-377.

32. Sawada Y., Hanano M., Sugiyama Y., Iga T.: Prediction of the disposition of beta-lactam antibiotics in humans from pharmacokinetic parameters in animals. J Pharmacokinet Biopharm 1984, 12, 241-261.

33. Zheng N., Wang J., Han R., Xu X., Zhen Y., Qu X., Sun P., Li S., Yu Z.: Occurrence of several main antibiotic residues in raw milk in 10 provinces of China. Food Addit Contamin Part B 2013, 2, 84-89. 